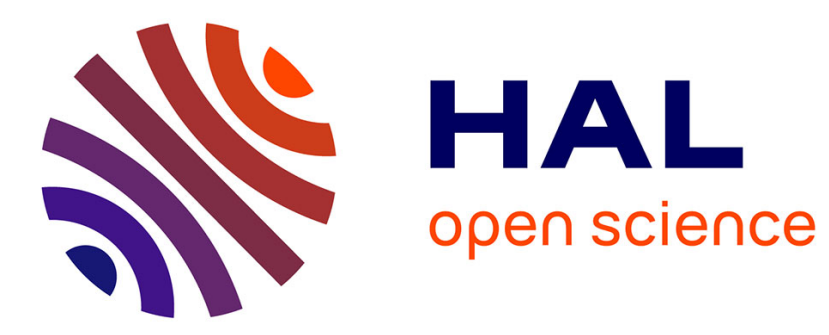

\title{
The Launch of Innovative Product-Related Services: Lessons from automotive telematics
}

\author{
Sylvain Lenfle, Christophe Midler
}

\section{To cite this version:}

Sylvain Lenfle, Christophe Midler. The Launch of Innovative Product-Related Services: Lessons from automotive telematics. Research Policy, 2009, 38 (1), pp.156-169. halshs-00401124v2

\section{HAL Id: halshs-00401124}

\section{https://shs.hal.science/halshs-00401124v2}

Submitted on 7 Jul 2009

HAL is a multi-disciplinary open access archive for the deposit and dissemination of scientific research documents, whether they are published or not. The documents may come from teaching and research institutions in France or abroad, or from public or private research centers.
L'archive ouverte pluridisciplinaire HAL, est destinée au dépôt et à la diffusion de documents scientifiques de niveau recherche, publiés ou non, émanant des établissements d'enseignement et de recherche français ou étrangers, des laboratoires publics ou privés. 


\title{
The Launch of Innovative Product-Related Services:
}

\section{Lessons from automotive telematics}

\author{
Sylvain Lenfle ${ }^{\mathrm{a}, *}$, Christophe Midler ${ }^{\mathrm{b}}$ \\ ${ }^{a}$ Université de Cergy-Pontoise - 33 boulevard du port, 95011 Cergy, France \\ ${ }^{\text {b}}$ Centre de Recherche en Gestion, Ecole Polytechnique - 1, rue Descartes, 75005, Paris, France \\ Accepted for publication in Research Policy by M. Callon on october 14, 2008 after one revision
}

\begin{abstract}
In the literature on new product development, most existing studies on the end of the design process concentrate on managing ramp-up in the field of manufactured products. This situation poses a problem at a time when our economies increasingly depend upon services and products are more and more related with sophisticated services that provides value for customers and producers. This article examines the management of the final phases of the design process of an innovative product-related service. Our research thus makes three contributions: 1) An analysis of the implementation process shows that the simultaneity of the production and consumption of a service means that three types of learning - technical, sales and uses - take place at the same time. Launch management strategies have thus to be adapted. 2) An analysis of the data collected confirms this difference by bringing to light great contrasts in these different aspects of learning. 3) This led us to identify a field that needs exploration by researchers in product and services innovation: the design of the sales process. Furthermore we underline two scenarios to manage the launch of innovative product-related services.
\end{abstract} Keywords: innovation; services; automotive telematics; sales process; product development organization.

\footnotetext{
* Corresponding author. Tel : 33.6.84.98.49.18. E-mail addresses : slenfle@hotmail.com (Sylvain Lenfle), christophe.midler@polytechnique.edu (Christophe Midler)
} 


\section{Introduction and research question}

The terms product and service are often confused in both the literature and in every day speech. Authors as Edvardsson et al. (2000) maintain that products and services concepts cannot be clearly disconnected. They argue that a product can be defined as a combination of goods and services, their relative weight differing between them. The market of mobile "smart phones" is a good example of this tight connection between the physical product world and the immaterial service one. Furthermore, even in traditional services sectors innovation relies on the development of innovative products to support the service: the Airbus A380 or the French TGV are good example of this trend. Figure 1 illustrates how the relative service content varies across a range of different products.

\section{INSERT FIGURE 1 ABOUT HERE}

In this paper, we will define Product-Related Services (PRS) as services that are closely associated with goods in products. Expanding the service content of products has been for years a major trend in business strategy (Furrer, 1997; Gadrey 2003; Cusumano, 2004; Magnusson 2003). This does not mean that physical goods disappear from our universe but that they are more and more associated with complex services that enhance the product value for customers and provide interesting business models for producers.

Developing innovative product-related services (PRS) is therefore a major concern for firms in a wide range of industries. This furthermore raised interesting theoretical questions. Indeed, most of the works on New Product Development are focused on the field of physical goods. As Thomke (2003) observed, this is the likely explanation for the relative lack of proven methods for the development of new services. Indeed, existing work on innovation in services agrees on one point: in service companies, the process of design/innovation is relatively informal, providing a partial explanation for the problems frequently seen in the development of new services, such as missed deadlines and inadequate quality (Gallouj and Gallouj, 1996; Jallat, 2000). This is all the more 


\section{RESEARCH POLICY - FinAL VERSION - OCTOBER 08}

regrettable given that, as we just said, service innovation is not limited to "pure" service companies (banks, insurance, transport, business services etc.).

Using an inductive methodology, this article will examine the management of the final phases of the design process of an innovative product-related service. While the literature on service innovation proposes theoretical models of the design process (Lovelock, 1984; Scheuing \& Johnson, 1989; Edvardsson et al., 2000) it does not pay much attention, as the literature on physical goods (see Krishnan and Ulrich review, 2001), to the final phases of the process (ramp-up, to the extent that this concept has much meaning for services, and marketing) ${ }^{1}$. They agree on the importance of conducting tests before service launch, but also show that these tests are rarely performed in practice (Eiglier and Langeard, 1987; Gallouj and Gallouj, 1996; Jallat, 2000). There is, however, reason to believe that these final steps in design play a crucial role in the success or failure of a new service, just as they do for physical goods.

This article will thus make three contributions. An analysis of the implementation process in the case of product-related services shows, first, that the concept of ramp-up is insufficient for understanding the phenomena involved in the launch of an innovative service. The simultaneity of the production and consumption of a service means that two types of learning - technical and sales - take place at the same time. The commercial dimension is not treated in studies on ramp-up, and it is therefore necessary to draw on other literature. We thus bridge two fields of literature: product development and marketing and propose a theoretical framework to understand the problems raised by PRS launch. Second, an analysis of the data collected confirms this difference by bringing to light great contrasts in these two aspects of learning. This led us to identify a field that needs exploration by researchers in product and services innovation: the design of the sales process. We thus propose two contrasted scenarios for the evolution of PRS development practices

\footnotetext{
${ }^{1}$ A bibliographical search in academic databases reveals that this issue has not been covered by any article in the specialist journals on production management (Production \& Operations Management Journal), nor in journals on services (Journal of Service Research, International Journal of Service Industry Management).
} 


\section{RESEARCH POLICY - FINAL VERSION - OCTOBER 08}

We begin by discussing the notion of a product launch and showing that this involves two different processes: the ramp-up of a production system and a sales launch. We then study the transferability of this concept to the world of services (§2) and we describe (§3) the research site, the service under study and our methodology. Section 4 presents the data. An analysis of these results shows the relevance of the results obtained in the case of products, as well as their limitations (§5). Finally this case also suggests that the development of the sales process for a product or service has still not been given great attention and discuss the implications of this situation. This led us to propose two scenarios to improve the efficiency of innovative PRS launch (§6). We conclude by pointing out that this is an important area for researchers in the management of new product development and innovation.

\section{The launch of a new product: physical goods vs. services}

In their critical review of the literature on new product development, Krishnan and Ulrich (2001) put ramp-up and product launch in the same phase; however, in the rest of their article the only work they cite in fact concerns ramp-up of the production system. We feel that this is indicative of the ambiguity of research on new product development, which - as the review of Krishnan \& Ulrich illustrates by default - harbours a significant technical bias and leaves aside the issue of the commercial launch. Therefore, we here consider product launch to incorporate what are actually two different processes:

- The start-up of production in normal conditions, generally called ramp-up.

- The commercial launch of the product.

The literature on new product development, which is already sparse on the first issue, is silent on the second, which is, on the other hand, dealt with in the literature on marketing and sales. The lack of communication between these two fields is due, in the case of physical goods, to the decoupling of these two processes. Chronologically, ramp-up precedes marketing, even though in practice there is some overlap. The literature on marketing thus assumes that products are available in the desired quantity and quality. This hypothesis is of some relevance, to the extent that the time gap 


\section{RESEARCH POLICY - FinAL VERSION - OCTOBER 08}

between the two processes ${ }^{2}$ makes corrections possible if, for example, the products are not of the required quality. Before studying the case of services, it is necessary to present the main results of this research, which we will consider in turn.

\subsection{Ramp-up of manufactured products}

In the literature on new product development, the final phases of the design process are mainly studied under the concept of "ramp-up", which designates "the period when the normal production process makes the transition from zero to full-volume production, at or near the targeted levels of cost and quality" (Terwiesch et al.. 1999, p. 4). As is specified in Wheelwright and Clark (1992, p. 8): "In ramp-up, the firm starts commercial production at a relatively low level of volume; as the organization develops confidence in its (and its suppliers') ability to execute production consistently and in marketing's ability to sell the product, the volume increases. At the conclusion of the ramp-up phase, the production system has achieved its target levels of volume, cost and quality." Ramp-up thus occurs as the last stage of development: the designs of the product and of the process are complete; prototypes have been made and tested; and now the transition is made to production in real conditions. The goods produced in this phase are intended for sale; goals for yields and quality thus play a major role.

Ramp-up is therefore the ultimate test of the quality of the design work. Research on the subject has shown that it must be viewed as a key learning opportunity. It has revealed three important points in the case of physical goods, as follows:

1. The fundamental role of the design work preceding ramp-up (strictly speaking) and the way the project as a whole constitutes preparation for this phase (Langowitz, 1988; Clark and Fujimoto, 1991).

2. The importance companies place on the management of this phase, as more and more frequently they set up teams specifically to manage it. Implementation is thus treated as an extension of the innovation process (Leonard-Barton, 1988). Terwiesch et al. (1999) show the positive impact the

\footnotetext{
${ }^{2}$ Generally, production begins before marketing, if only to supply the dealer network.
} 


\section{RESEARCH POLICY - FINAL VERSION - OCTOBER 08}

establishment of specialized teams for managing this phase has had in the case of the hard disk industry.

3. And, consequently, the differences in performance observed among firms that adopt very different strategies in this area. Research in this field has, for example, shown the impact of variables like training and change management (Adler and Clark, 1991), experimentation strategies (Terwiesch and Xu, 2001; Terwiesch and Bohn, 2001), industrial strategies (Clark and Fujimoto, 1991), and capitalizing on previous experience (Charue-Duboc, 1995).

This research thus emphasizes the role of "induced learning” (Dutton and Thomas, 1984), i.e. deliberate managerial action to improve the efficiency of ramp-up. This fits in with recent literature on learning curves (Lapré et al., 2000), which underlines the need to organize the feedback in order to accelerate knowledge creation and transfer.

\subsection{The commercial launch of a new product: preparing the sales performance}

If we now turn to product launch, we have to consider the literature on marketing, sales and strategy. These studies have examined the impact of the strategy adopted during launch on the diffusion of innovation and, consequently, on a company's profitability. Thus Lieberman and Montgomery (1988) devote great attention to the advantages and strategic risks of the first-mover, whereas the classic marketing texts (for example, Kotler, 2003) highlight the main strategies possible during the launch of a new product. At a general level they oppose the strategies of a mass launch mobilizing every marketing lever, at great cost, to accelerate diffusion - in favour of a more prudent approach that focuses on early adopters and that limits the resources committed. At an operational level, this research has led to significant results:

1. Rogers (1983) underlined the importance of early adopters of a new product regarding the process of diffusion, thus highlighting the importance of choosing the first customers to be targeted at launch. More recently, Moore (1995) has shown the limits of this reasoning and the need to adapt a company's strategy to "cross the chasm" that separates early adopters from the mass of potential customers. 
2. Customers are not the only targets at launch; for a company to gain acceptance for its innovation, it must also convince distributors (including its own network), who will sell and recommend the product to customers, and producers of related goods, who in some cases determine how attractive it is (e.g. Gawer and Cusumano, 2003). This process of convincing and training partners is long and expensive.

3. The Marketing literature on new products discusses the impact of the marketing mix on how consumers greet an innovation (Manceau, 2003...). It emphasizes in particular:

a. The importance of the simplicity of the initial offer in order to facilitate customer uptake.

b. The role of communication that help explain the benefits of the product and contribute to promoting its image among future purchasers. In this perspective, the tests organized at launch can play a significant role in adoption.

c. Various price strategies, depending on whether the goal is rapid market penetration (low price) or a quick return on investment (skimming through a high price).

d. The key role of the salesmen "performance", in the theatrical sense of the word (Barbier 2002). Barbier ethnographic analysis of sales practices in car selling show the complexity of the sales sequence, its improvisational content and, therefore, the difficulty to rationalize it.

4. Finally research on sales management emphasizes the role of sales force involvement in the success of new product launch (di Benedetto, 1999). To carry out this role most effectively, it shows that salespeople themselves must adopt the new product through their commitment to the innovation and resulting effort devoted to its sale (Hultink and Atuahene-Gima 2000). To obtain and reinforce such commitment and effort, sales management often recognizes the need to adjust its strategy as a response to the new product launch (Michael et al., 2003).

\subsection{The specific character of services and its implications}

Even though the two trends in literature provide solid results in the case of physical goods, the question of their transferability to services remains. Four points need to be taken into account. 


\section{RESEARCH POLICY - FinAL VERSION - OCTOBER 08}

1. The convergence of researches on physical goods and services. First it is interesting to note that, with regard to the issue of the launch itself, the results are similar to the case of physical goods. Eiglier and Langeard (1987) thus emphasize the importance of clear communications and the simplicity of a new concept offered to customers. Likewise, Lovelock (1984) and Scheuing and Johnson (1989) point out the importance of training front-office personnel given that services are coproduced with customers, without, however, explaining which actions might be relevant. Such results are interesting because, as Thomke (2003) observed, the focus in the literature on material product innovation is the likely explanation for the relative lack of proven methods for the development of new services. Indeed, existing work on innovation in services agrees on one point: in service companies, the process of design/innovation is relatively informal, providing a partial explanation for the problems frequently seen in the development of new services, such as missed deadlines and inadequate quality (Gallouj and Gallouj, 1996; Jallat, 2000).

2. Production ramp-up and commercial launching cannot be isolated. However, due to the structural characteristics of services, it is not possible to separate production and marketing (Eiglier and Langeard, 1987; Grönroos, 1990). As services are not material goods, they cannot be stocked. They are also co-produced in interaction with the customer. The presence of the customer raised specific difficulties since he is very difficult to control. In these conditions, i) implementing the service can hardly been experimented properly and extensively before the sales and customer real experience of the service; ii) it is very difficult to "correct" defects ${ }^{3}$, and iii) customer dissatisfaction is immediate and frequently insurmountable (Zeithaml et al.., 1990). The first marketing is thus very much a moment of truth (Norman, 1991) that will, to a great extent, determine the success or failure of the new service. We will consider the consequences of simultaneous production and sales activities later in this paper.

3. Services Ramp-up. To our knowledge, the notion of ramp-up has never been used in the case of services. This raises a question about whether this concept and the results from the realm of physical goods are applicable. In this latter case, monitoring ramp-up particularly involves the

\footnotetext{
${ }^{3}$ Unlike manufacturing plants that can "take back" a product before marketing it, even if this is costly.
} 


\section{RESEARCH POLICY - FINAL VERSION - OCTOBER 08}

determination of an observation point (in general, the factory) and the definition of indicators used to manage the phase (in general, productivity and quality). Studies on the subject thus typically measure the time required for different plants to achieve "normal" levels of productivity and quality and/or to explain any differences according to the strategies implemented before and during ramp-up (cf. section 2.1). In the case of services, we will hence have to determine the appropriate performance indicators and deal with the problems posed by the dispersed, heterogeneous character of the network.

4. User learning and involvement. Finally service co-production gives the customer-user a key role in the design and implementation of innovative services. Therefore user learning ought to be a central concept in service development and ramp-up (as workers learning programs are central variables in production ramp up efficiency). In fact, the question of the ability of the customer to use the new service properly and then benefit from its value is not a specificity of service vs. physical good, but a general question for radical innovation that need new competencies to be learned by users. We will come back to that remark in $\S 5$. Considering the product user as an important actor in the new product development is therefore one of the major trend in contemporary innovation management literature. Alam (2002), for example, propose a framework to classify different types of user involvement and show that it is more common nearer launch, and increases with project uncertainty. Moreover, users are also involved after launch, for example to evaluate and suggest improvements that will facilitate, or increase, the product use.

According to these results of the literature, the analysis of the launch of product-related services will have to focus simultaneously on technical tamp-up, the involvement and "performance" of salesmen and the organization of user's learning. In traditional product development processes, these three variables can be clearly isolated and sequentially organized. Since this is not the case for PRS, the question becomes: what are the processes adapted to their development and launch? By studying the case of telematics services, we will be able to specify the phenomena involved during the launch of an innovative product-related service and to show the value and limits of observations from the study of physical goods. 


\section{RESEARCH POLICY - FINAL VERSION - OCTOBER 08}

\section{Research Design and data}

To study these questions we decided to focus on the auto industry. Actually, car manufacturing constitutes a typical example of an industry that offers a product-service pair (Eiglier and Langeard, 1987). Even if historically the product-service couple is in this case dominated by the product, car manufacturers offer their customers a wide range of services aimed at facilitating the car's purchase (credit), repair (maintenance) and availability (breakdown assistance), or all three simultaneously (via a combined monthly fee). This trend to develop car-related services has been recently boosted by using Information and Communication Technologies (ICT) to offer customers new types of "telematics services" (navigation services, remote diagnostics, emergency calls and more). Making room for new service possibilities is a significant innovation for car manufacturers, which are embarking on a field that they have not yet mastered.

To study these questions, in 2001 we made contact with one of the principal European car manufacturers, here identified as Telcar for reasons of confidentiality. After a presentation of our previous research on managing innovative projects (Lenfle and Midler, 2001), Telcar gave us permission to study the case of the Emergency and Breakdown Call (E/B Call) service, whose development was then just beginning. Before describing our methodology for data collection in detail, we shall begin by providing an overview of this service and analyzing the design problems that it raises.

\subsection{Research Site}

We decided to focus on the case of E/B Call, service that began at Telcar in $2001^{4}$. We narrowed our focus to one service because field-based research (see data collection methods, below) required an in-depth observation of the design process. Moreover, E/B Call represents a typical case of product-related service innovation. Actually, as the name indicates, the concept involves offering buyers of new vehicles a service that allows them to call a number for help in case of an accident or breakdown. The call (made automatically in an accident) is used to determine the vehicle's precise location and organize assistance. 
The service may appear to be an a priori extension of the assistance services that have long been offered by car manufacturers. However, a detailed analysis of the design work (Lenfle, 2004) shows that this represents a major breakthrough in several areas simultaneously. It requires:

1. Developing onboard equipment that enables communication with and location of the vehicle, including when a crash occurs. It is thus necessary to coordinate the design of the service and the onboard equipment ${ }^{5}$.

2. Solving the legal issues raised by an emergency service (e.g. who is responsible if a problem arises during the emergency procedure?).

3. Setting up a front office, in the knowledge that the one offering the service (the dealer network) is not the same as the one performing it (a partner specializing in assistance).

4. Designing and setting up a complex back office, comprising:

- A telecommunications infrastructure that can locate the vehicle in an extremely short time and with a high degree of reliability.

1. Information systems that can record service contracts and handle invoicing, and then deal with internal data to manage customer relations.

5. Developing a business model that ensures the financing of a service that, according to all those involved, is "difficult to sell". In this case the company decided to deduct a percentage from the price of the onboard equipment to finance the service.

The E/B Call case is therefore relevant to the study of designing innovative product-related services. In fact, this corresponds to a situation in which innovation simultaneously modifies both the technical skills of the firm and its relationship with the market (what Danneels (2002) describes as "pure exploration”). Telcar will therefore be obliged to develop new skills in both these fields. Furthermore, Telcar was the first to propose this service in Europe in this segment ${ }^{6}$. The modification of the relationship with the market is of particular interest in our research topic since, as we shall see, the

\footnotetext{
${ }^{4}$ For reasons of confidentiality, names and dates have been changed and/or disguised.

${ }^{5}$ And, of course, the vehicle. But the project in charge of the vehicle always keep a back-up solution if the onboard equipment and/or the new service are not ready on time.
} 
launch of this service will presuppose a major training effort within the network and customer learning.

\subsection{The problem: Integrating technical development and commercial performance \& user}

\section{learning}

The case of the E/B Call helps us understand the phenomena involved in launching an innovative service. For this purpose, we propose using the model proposed by Shostack (1981) and then developed by J. Kingman-Brundage (1989). This tool, called a "blueprint", helps to identify the main steps involved in delivering the service and, for each step, the process and people involved in it. Two levels can be distinguished, corresponding to the classic distinction between front and back office:

1. People in contact with the customers (interaction line).

2. The process supporting these people, which is invisible to the customer (line of visibility). Applying this model to the case of the E/B call, we obtain the following diagram, which represents a simplified version of the "servuction" process and consists of only two steps (Figure 1). This blueprint helps us understand the complexity of the phenomena involved in the launch of an innovative service like E/B Call. Two points in particular distinguish the case of services from that of physical goods.

\section{INSERT FIGURE 2 ABOUT HERE}

First, due to the co-production and non-material nature of the service, the system must be operational from the first day it is marketed (a customer could have an accident only moments after subscribing to the service). Unlike the situation with regard to products, the start of production cannot be dissociated from the start of marketing. The ramp-up and marketing phases are thus intertwined. This simultaneity creates additional problems for the project team: unlike physical goods, it is impossible to take back a service after a defect has been noticed. As is clear, however, there are many potential sources of defects: they could come from the front office and/or the process established, in

\footnotetext{
${ }^{6}$ Only BMW, with his Assist service, proposed a similar service for high-end 7 series vehicles.
} 


\section{RESEARCH POLICY - FINAL VERSION - OCTOBER 08}

this case the registration of customers during the sale, the localization of the vehicle and the organization of assistance ${ }^{7}$.

Second, while the notion of ramp-up emphasizes the technical aspect of learning with regard to the capacity to produce the product correctly, in this case the two processes of learning identified in Section 2 take place simultaneously:

- The first (right part of Figure 1) involves the production of the service itself, i.e. locating the vehicle and organizing assistance or repairs. It concerns those involved in the assistance system, as well as the entire communications and assistance back office, which, it should be recalled, is where the main innovations are concentrated.

- The second (left part of Figure 1) concerns the effectiveness of the process of selling the service. In the case of the E/B Call, this takes place mainly at the dealership and involves the sales and marketing staff and the customer above all.

Consequently, these two processes involve groups that only partially overlap. The technical complexity of the service is thus amplified by organizational complexity (see figure 2 for a description of the actors involved in the design process). As we shall see, the two processes present highly contrasting evolutions. In the remainder of this article we shall call these Process 1 and Process 2 respectively.

\subsection{Data collection}

Data collection was performed over a three-year period. This enabled us to take part in the real-time design process and, in particular, in the first 17 months of the marketing of this new telematic service. Consequently, we were able to follow and analyze the whole design process, and then observe its results. To do this, we received support from the Project Manager as well as from its main sponsors. As a result, we had virtually unlimited access in the field. The duration and frequency of the interaction with the design team enabled us to follow the development of the design process

\footnotetext{
${ }^{7}$ These are not all equally serious. Errors in registration hurt the company first, as it will experience difficulties in managing its customer relations. On the other hand, failure to locate the vehicle calls into question the very reason for the service.
} 


\section{RESEARCH POLICY - FINAL VERSION - OCTOBER 08}

accurately and gain access to data sources usually closed to outsiders. More specifically we relied on three sources of evidence:

1. About 70 semi-structured interviews were conducted with 30 participants in the project. These interviews involved both functional managers (IT, marketing, sales...) and the project team in charge of designing the service. Individual interviews lasted from one to two hours. Frequently they were complemented by shorter, follow-up interviews that enabled further exploration of some aspects and provided updates on the progress of the project since the previous meeting. During these three years we also had many informal conversations and e-mail exchanges with team members.

2. We passively participated in all relevant meetings on the design of the E/B Call. In particular:

- The monthly plenary meeting at which the progress of the project was discussed,

- The working groups designing the various elements of the "servuction" system,

- After launch on the market, the monitoring meetings that brought all the parties involved together every month.

As a result, a typical week consisted of taking part in one to three meetings as well as one to three interviews with staff on specific topics. The intensity of the contacts depended on the progress of the design work. Some weeks, we held only one interview, whereas others saw us spending two full days with the team.

3. Written documents supplied by the company (reports, minutes of meetings, PowerPoint presentations, and so on), which enabled us:

- To reconstruct the history of the project, to prepare for interviews and to obtain corroboration of interviewees’ statements;

- To obtain accurate data about the way the project was organized. Working as closely as we did with the project manager enabled us to map the participants in the project completely. Subsequently, during the market launch phase, we received copies of the various scorecard indicators set up to monitor the launch. 


\section{RESEARCH POLICY - FINAL VERSION - OCTOBER 08}

Following the paradigm of grounded research (Miles and Huberman, 1994; Eisenhardt, 1989; Yin, 2003) our analysis was built on detailed field notes - interview notes, transcripts of project meetings, company documents - compiled into detailed case studies for each phase of the design process. This process was iterative as the cases were frequently updated after follow-up discussions with respondents. More precisely each case study report was re-read by key informants and discussed during bi-annual research meetings involving the project manager and members of the project steering committee. These meetings simultaneously enabled the results presented to be confirmed and the directions taken by the research to be discussed.

\section{Results: the design and launch of E/B Call}

To understand the problems raised by the launch of an innovative service we begin by presenting the data collected, both qualitative and quantitative. As shown in Section 2, to comprehend the progress of the launch, we must first examine the design process. We shall begin with this question before studying the launch process itself.

\subsection{The design process}

When our research began in June 2001, the Telematics project was underway since 1998. A new project manager has just been appointed. Indeed, since its beginning the project has faced many difficulties and did not succeed in launching the promised services ${ }^{8}$. Telcar Management thus decided to refocus the project on the development, as a first step, of the E/B call. Thus in June 2001 the work of designing the technical infrastructure (Process 1) and the methods of marketing (Process 2) of E/B Call had been underway for six months. At the time, the launch onto the market was planned for March 2002. The design process was managed by a project team in which, as usual, two kinds of people could be distinguished:

- The telematics platform (TP), which is a dedicated and co-located project team of around twenty people, constituted the core of the project. This facility, reporting directly to the Innovations Division, and with the support of the Board of Directors of Telcar, ensures 


\section{RESEARCH POLICY - FINAL VERSION - OCTOBER 08}

coordination of all activities related to telematics (exploring new services, prototyping, preparing for launch, designing onboard equipment, and so on).

- Correspondents from the functional departments, specializing in telematics, who were often present in the platform, but who remains within their original department. There were five of these, representing the product, after-sales, CRM and information systems.

Figure 3 summarizes the principal stages in the design and shows the points at which these various people became involved.

The design of the technical infrastructure (Process 1) was carried out by the telematics platform with support from the functional correspondents. The year 2001 was devoted to choosing communications protocols, to selecting and then monitoring the suppliers who were to ensure that the chain of communications would work, and to setting up, on a specialist partner firm's premises, the assistance and emergency platform that was to provide the service. This work, whose completion was initially scheduled for February 2002, was in fact only completed in May because of difficulties that were encountered, especially with setting up the communications infrastructure and the assistance platform. The initial test in May thus revealed problems that could have led to the project's being cancelled: SMSs that were held up or lost, problems in locating and identifying vehicles, and major variability in service quality depending on the assistance platform operator. Corrective actions were therefore undertaken which, for example, led to modifications to service platform operators' scripts and improvement in their training. Two further tests were organized before the infrastructure could be declared operational in September 2002. In the meantime, the E/B call missed the launch of a new vehicle.

\section{INSERT FIGURE 3 ABOUT HERE}

Designing the marketing methods (Process 2 in Figure 1) took place in parallel. This was guided by correspondents of the Product Division, with support from the TP, and from the After-

\footnotetext{
${ }^{8}$ This difficulties were partly internal (technical problems, lack of communication...) and partly strategic (failure of a partnership, collapse of the internet bubble...). Note that this is typical of radical innovations (e.g.
} 


\section{RESEARCH POLICY - FINAL VERSION - OCTOBER 08}

Sales, Customer Relations and IT Systems Departments. At this stage, the Sales Department was only kept informed of work in progress through his involvement in the project steering committee (dotted line on Figure 3). In November 2001, a presentation on the subscription process given to the Sales Department gave rise to heated debate. What was originally planned was that the service should be activated in the dealership ${ }^{9}$, a specific contract should be signed, and a service registration call made jointly with sales staff for customer data to be recorded. The Sales Department considered this to be too complex and intrusive. In April 2002, therefore, it appointed a correspondent to assist with the design of a second subscription process. The latter enabled simplification of the IT systems to be used by the network, but without changing the logic of the procedure in any fundamental way, however. As a matter of fact, when consulted in March, the Legal Division insisted that a specific contract be signed so as to limit the manufacturer's liability, whereas the Customer Relations Department insisted that the service registration call be kept instead. The conflict lasted until October 2002, on which date the project steering committee imposed the implementation of the modified procedure. Two people were then designated by the Sales Department to assist with implementation. But the project was already late. Thus, because of lack of time, the procedure could not be tested in a real-life situation. No dealership was involved to confirm it. Furthermore, the new correspondents pointed out problems that had been ignored up to that point. For example, a visit to the Training Centre in October 2002 revealed that not all dealerships had the equipment planned for use in activating the service. Similarly, these repeated delays had led to the adoption of stop-gap solutions: contracts were initially recorded manually, network training was limited to putting a training module on the intranet, and no incentive scheme had been planned for sales staff, both for technical reasons (complexity of IT systems) and because the sales department considered the service peripheral. Finally the organization of customer learning was largely ignored.

\footnotetext{
Van de Ven et al.. 1999).

${ }^{9}$ Using a computer connected to the vehicle, the dealer would activate the service if the customer subscribed.
} 


\subsection{Progress of the launch}

The service was finally launched in February 2003, 12 months later than initially planned. The difficulties encountered in service design led the project managers to define three different indicators to monitor the implementation of service marketing:

On the technical side, the reliability rate measures the ratio between the calls located properly and the total number of calls. It estimates the reliability of the back office, which comprises the telecommunications infrastructure set up to locate vehicles and then organize assistance. This first indicator thus measures the quality of the "technical" design work performed by the team (Process 1).

On the commercial side two indicators have been defined:

a. The rate of contract subscriptions measures the ratio between the number of customers who might subscribe (those whose car is fitted with telematics equipment) and those who actually subscribe. It measures the effectiveness of the "internal marketing" work performed by the project team. Note that there are two particularly interesting features concerning the emergency call service offered by Telcar:

- It is free for customers who bought the associated onboard equipment; as a result, the contract subscription rate is not influenced by price considerations and could be considered a relatively "pure" measure of the work done to design the service marketing set-up. Nevertheless, even free, the customer may not subscribe because 1) he doesn't want the service (e.g. he considers it too complex ${ }^{10}$ ) or 2) the dealer doesn’t propose it.

- Likewise, the company decided not to promote the service initially except through its network; it was thus mainly sales personnel who were promoting the service.

b. The rate of registration calls measures the ratio between the number of customers actually subscribing to the service and the number of registration calls really made. As already explained, the marketing process provides for a call between the service platform and the customer to record certain customer data. So there may be cases where the customer effectively subscribe the service but the dealer don't make this registration call ${ }^{11}$. This third rate helps to measure the extent to

\footnotetext{
${ }^{10}$ For example he has to procure a twin sim card from his telco provider.

${ }^{11}$ However the service works in this case.
} 


\section{RESEARCH POLICY - FINAL VERSION - OCTOBER 08}

which the network has assimilated the procedures designed upstream, the efficiency of the training process.

The following graphics page (Figure $4 \& 5$ ) presents the changes in the three preceding indicators over a 17-month period, starting at service launch. At this time (June 2004), the team considered that the system was functioning "normally", at least from a technical viewpoint. Indeed the reliability rate for localization has stabilized since the end of March at above the initial goal of 95\% (dotted line on the figure 3). This gives rise to several observations.

First, at the technical level, the tests performed before service marketing were not adequate to deal with all the uncertainties. The first quarter was marked by a low reliability rate (blue curve). To resolve this problem, from March 2003 the Manager of the Telematic Platform allocated one member of the design team to monitoring the service. He also implemented a monitoring and problem solving procedure for the problems detected. In this way, every defective call was systematically analyzed. The objective was to reach a reliability rate for locating vehicles of better than $90 \%$, as initially planned. A committee to monitor the service meets every month to keep abreast of the situation. Actions implemented then enable identification of the causes of these problems, which concern both the telecommunications infrastructure (e.g. lost SMSs) and the subscription procedure (problems with the vehicle configuration software).

A continual improvement in the reliability rate was observed: in 17 months, it rose from less than $50 \%$ to stabilize at above $90 \%$ in the $11^{\text {th }}$ month, achieving the targeted $95 \%$ by the end of the $14^{\text {th }}$ month (Figure 4). A detailed study of the changes in this rate provides greater detail regarding the technical ramp-up. Figure 5 thus shows that the team managed to solve the main problems between the fourth and eighth months following launch. Between these two dates, the reliability rate, this time calculated on a weekly basis, rose from below $20 \%$ to $90 \%$. Variations in this rate, in particular the trough seen for Week 22, nevertheless show the difficulty for a car manufacturer with regard to mastering a completely innovative back office. In September 2004, considering the progress that had been made, the project manager decided to suspend the procedure for handling anomalies. A scorecard indicator used for monitoring purposes replaced it. 


\section{INSERT FIGURES 4 \& 5 ABOUT HERE}

If we now consider the rates for subscription and registration calls, i.e. the "commercial" dimension of ramp-up (process 2), the situation is very different. These two rates have a dual characteristic:

- They are relatively low (between 30 and $40 \%$ for the subscription rate ${ }^{12}$, below $30 \%$ for the service registration calls).

- They are stable over time, reflecting the relative lack of learning during the period under consideration.

The organization set up here is very different from the technical aspect of the service. Four people work part-time on this question, covering the whole country. They took part in the procedure design process, but do not belong to the Sales Department. Their access to the distribution network is therefore limited and every action must be negotiated with the Sales Department. Furthermore, the latter, due to the innovative nature of the service and its operational complexity, has remained hesitant about launching the service and is not involved in monitoring. As a result, over these three years, no member of the Sales Department has attended any of the telematics plenary sessions, nor meetings of the service launch monitoring group.

After the launch, these people work focused on two aspects. First of all, they participated in resolving the most urgent problems detected during the launch. In May and June 2003 all efforts were concentrated on updating the vehicle configuration software, which had been full of bugs, and on modifying the procedure to match. Secondly, they attempted to catch up on the previously accumulated delay by organizing training seminars for dealers wherever possible (for example, in March 2003 with one of the 5 regional sales offices). These training activities were continued throughout the entire period with greater or lesser intensity depending on staff availability and the relationship with the Sales Department. Nevertheless, they did not provide a significant improvement in the rates of subscription and of service activation calls (Figure 4). 


\section{RESEARCH POLICY - FINAL VERSION - OCTOBER 08}

The data collected on the E/B Call case thus reveals two very different processes, depending on whether the "technical" or "commercial" aspect of the service is considered. The analysis of these differences is the subject of the next section.

\section{Analysis}

To explain the differences in development between the "technical" and "commercial" dimensions of the service, we shall use the work introduced in Section 2. More precisely, this research leads us to analyze, for each of the two processes identified, the way the design process was carried out, and then the way the launch itself was organized. On the first point we shall use models of project analysis that have become standard (Wheelwright and Clark, 1992). On the second point we shall concentrate, as suggested by recent research on learning (Lapré et al.., 2000; Terwiesch and Bohn, 2001), on studying the organization of the feedback between data collected in the field and corrective actions taken by the team. We shall begin by explaining the changes in the reliability rate, and then as a contrast, those in the contract subscription and service registration call rates.

\subsection{Process 1: Service Infrastructure}

\section{Upstream design work}

As we showed in the previous section, the organization of the service infrastructure design work (Process 1) fell to a dedicated team (the Telematic Platform and its Correspondents), which brought together all the necessary skills, with the notable exception of sales. This form of "heavyweight management” (Wheelwright and Clark, 1992) facilitated communication between team members and enabled the establishment of the communications infrastructure and of the service platform to be handled simultaneously. Despite everything, the foregoing data show up a large delay in the design phase. This shows the difficulties inherent in a "pure exploration" situation. As a matter of fact, for everyone involved, this kind of service was completely new. Unable to draw on any previous experience, they simply found out about and resolved the various problems as they went along. Consequently, as the infrastructure manager explained, "There are five possible sources of

\footnotetext{
${ }^{12}$ In an ongoing research with a telecommunication operator we observe, in the case of a paying service, a similar pattern. The ratio between the number of mobile phones able to provide the service and the number of
} 


\section{RESEARCH POLICY - FINAL VERSION - OCTOBER 08}

error in the system: the onboard equipment, the telecoms operators, the two suppliers in charge of routing the SMSs and the assistance platform. Since every link can go wrong through several causes, there is really every reason for it not to work." Thus, the low reliability rate of vehicle location calls during the first weeks of marketing was more indicative of the difficulty of perfecting an unprecedented telecommunications infrastructure than of inadequacies in the upstream design work.

\section{The role of monitoring and launch structure}

However this intense design work was to enable rapid improvements in performance during the launch. In particular, the tests were performed under real conditions, which made it possible, if not to eliminate all defects, at least to identify their possible causes. The team was thus prepared to handle the difficulties that arose during marketing. The design work had laid the foundations for understanding. It enabled the accumulation of knowledge as much about the causes of the problems encountered (what Lapré et al. term “conceptual learning”) as about the ways of resolving them (“operational learning”). The organization set up on the launch date was to rely on this accumulated knowledge. The procedure for analyzing the defective calls set up in March 2003 played a pivotal role. It was to enable feedback to be organized on the basis of the data collected. For each call, the engineers could seek out the causes of any problems in the system and try to correct them. The "observed interference" (Von Hippel and Tyre, 1995) thus generated a cycle of problem-solving that enabled full control of the system and thus of performance. In this way, the weekly reports of anomalies detected show that the causes of each were systematically sought out, and gave rise to experiments which provided confirmation that they were responsible AND solutions to be implemented. This support structure was thus to help in managing the "crises" arising when the service went on the market. The change in the reliability rate between the fourth month and the eighth reflects the difficulty as well as the effectiveness of learning.

customer actually using it is approximately $15 \%$. Interviews shows that this is not only a price problem. 


\subsection{Process 2: The sales and customer learning process}

\section{Upstream design work}

By contrast, the design work on the marketing process was much less intense. In this dimension of the project, the way the design process worked was similar to the lightweight or sequential operations whose limits were described by Wheelwright and Clark (1992). There were thus very logical weaknesses in this type of organization.

Downstream activities, in particular the sales department, were integrated belatedly into the project team (Lenfle and Midler, 2003). Furthermore, communication with the sales department was poor, irregular and took place mainly at the level of functional rather than operational management. Thus the main communication channel was with the representative of the sales department participating in the project steering committee. As one member of the team explained, "they were represented but never present. [As a result] We obviously have a problem with knowing just how the dealers network functions. Before, I used to know a dealer, so I could just find out. We should have brought them into the project. But we didn't do it. Besides, if I bring somebody in without telling Sales Department, I'll be in trouble. At the same time, however, if I go through official channels it takes six months to bring in somebody who only works three streets away from here!" This lack of communication, and consequently of knowledge, explains why the implementation problems were discovered so late, and the conflicts over the design of the subscription process (cf. Section 4). This caused a delay that led to neglect of the real test phases with one or more dealers to evaluate the procedure's effectiveness. So it was not possible to count on the knowledge accumulated during these tests (Thomke, 2003). Marketing thus became the real moment of truth. Finally, the marketing efforts, which are crucial to the success of an innovative product or service (cf. Section 2), could not be carried out effectively. This undoubtedly constitutes an initial explanation for the low number of subscriptions observed ${ }^{13}$. It posed a further problem that the managers of Process 1 did not have to

\footnotetext{
${ }^{13}$ It is striking to see the similarity between the slight involvement of sales and the situation of factories in the mid-1980s: process feasibility problems were discovered late because manufacturers were not much involved in the design process. With the implementation of concurrent engineering, the factories were involved upstream of
} 


\section{RESEARCH POLICY - FinAL VERSION - OCTOBER 08}

face: because of the delays, the initial level of knowledge, both conceptual and operational, was lower. This was to complicate the management of the launch considerably.

\section{The role of the monitoring and launch structures}

Nevertheless, while the functioning of the design process explains the difficult start-up of the services, this cannot explain the lack of learning over the period. Even here, we are faced with a paradox. The scorecard indicators set up show, right back to March 2003, the low rates of subscription to the service and of service registration calls. The absence of learning is therefore explained not by a lack of data but by the organization of the feedback between these data and staff in the field, i.e. in the dealer network. In the previous case, the effectiveness of that feedback was the reason for the improvement in vehicle location reliability. The data collected demonstrate that the same process did not take place in the sales dimension of the service. There are several reasons that explain this situation.

First of all, the situation was different with regard to the technical dimension of the service. There, what was involved was managing a largely automated technical system about which the team possessed a high level of knowledge. The difficulty here was managing the way a very heterogeneous network acquires learning. Dealers are scattered throughout the country, some being medium-sized companies in large urban areas, while others are very small family-run firms. The challenge here was thus 1) to monitor the functioning of the entire network, and 2) to ensure that both learning and the exchange of learning amongst dealerships were capitalized upon. Given the geographic dispersal of the dealers and the sales pressure they are subjected to, it is not at all likely that the transfer of knowledge will take place spontaneously. Furthermore, the way in which the design took place meant that the level of knowledge remained extremely limited, both about the functioning of the network and on the ways of involving it. The system for managing the ramp-up was thus to play an absolutely crucial role in this process.

development right through to the most operational level to review product/process designs. This was to play a central role in the shortening of product development observed in the early 1990s (Clark and Fujimoto, 1991). 


\section{RESEARCH POLICY - FinAL VERSION - OCTOBER 08}

Now, this management system was much less developed than in the previous case, although the task seems more complex to us. The data reveal that the staff in charge of the launch was not allocated to this task full time. The awkward relationship with the Sales Department meant that they could not benefit from direct access to the network. The latter was chary about launching this service and gave little support. Consequently, every corrective action has to be negotiated with the Sales Department, which lengthened the problem-solving cycles. Finally, in this context there was no systematic procedure for resolving the problems that were identified. This weakness in the support structure was particularly damaging. The dispersion and heterogeneity of the network severely complicated the management of the feedback between the collected data and action in the field. Actually, given the dispersion of the network, the average number of contracts signed per dealer is very low; no dealer thus has a sufficient base of experience to master the subscription process. The existence of a launch support structure is thus a sine qua non for the existence of a learning process ${ }^{14}$. Its role should consist of centralizing the learning acquired by the various dealers, making changes to procedures and assisting the network with any difficulties ${ }^{15}$. Its quasi-absence in the E/B Call case goes a long way toward explaining the stability of the curves.

Moreover this leads us to believe that the effects of this absence are cumulative over time. In fact, although research has revealed differences in ramp-up speed between different firms, we ourselves have observed an absence of learning in the commercial dimension of the service. It would therefore seem that the team had to pay the price for the problems encountered in the design phase. The late involvement of and the tension with the Sales Department, and the consequent delay, led the team to adopt stop-gap solutions, whether for raising awareness and providing training in the network or for incentive schemes (Section 4). The lack of internal marketing was particularly damaging since

\footnotetext{
${ }^{14}$ This has been demonstrated by the literature on products (cf section 2). The difference is that here the transfer must be managed in real time, whereas the product studies generally examine the consequences of the transfer in the case of two successive launches in different factories.

${ }^{15}$ Other case studies in the same company show the effectiveness of this type of structure, when it exists. These cases also demonstrate that for services training efforts are particularly long-lasting and costly: many people are mobilized months before the launch.
} 
it leads the Dealers to have either poor or nonexistent knowledge of the service. From that point on, the team was faced with a vicious circle: the initial subscription rate was low, and resources were not available to catch up on the work that had not been done previously. Since it was not equipped with the necessary knowledge of the procedures that were operating, the team's action was more like "firefighting”, whose limits have been pointed out by Lapré et al. (2000): it had to concentrate on urgent problems that were not detected at the design stage, there was insufficient time to understand the phenomena that were operating, and nothing could be done to improve the subscription rates. The lack of communication about E/B Call when it was launched, and of a specific incentive scheme for sales staff, provided the final complication for the procedure. There is thus every chance that the innovation will never make up for the accumulated lag, becoming locked in a non-learning cycle.

Our analysis of the collected data consequently reveals two very different learning processes. Process 1 was based on a dedicated support structure which drew on design work carried out beforehand, effective problem resolution procedures had been set up, and the team was able to take action to deal with the problems. Process 2, facing a more complex task, had to catch up with the task after the initial loss of time, but was without adequate ability to act, which explains the stability of the curves. Here the essential question concerns the involvement of the Sales Department. This forms the subject of our discussion.

\section{Discussion: two contrasted strategies to enhance the efficiency of innovative product-related services launch.}

The E/B call case demonstrates the difficulty of innovative PRS launch. This is due to the overlapping of three processes: the technical ramp-up of the service infrastructure, the design and implementation of the sales process, the need to explain to the customers and sellers the value and functioning of the service. From that point on we can consider two different, but complementary strategies to enhance the launch process:

- The first one, in line with the logic of concurrent engineering, emphasize the early involvement of sales personnel in the design process in order to prepare the launch, design the incentives, develop learning programs and so on. 


\section{RESEARCH POLICY - FINAL VERSION - OCTOBER 08}

- The second one takes into account the structural limits of the sales process to train the customer. Indeed, the registration call curve on figure 4 demonstrates how difficult it is to implement complex sales processes (see also Barbier, 2002). In this perspective, after-sales then become a key process to support customer learning. This second strategy has been largely developed software companies that emphasis the importance of efficient hotlines to follow their customer's experiences of innovations, help them to develop valuable use and last but not least increase their loyalty.

We discuss them below.

\subsection{Implementing concurrent design for PRS: conditions and limits}

The analysis of the E/B Call case thus shows both the importance of the sales process in launching innovative services and the difficulty of involving the sales personnel in the design process. This question has, however, not been given much attention. This clearly goes beyond the field of the literature on ramp-up. The paradox is that it is also given little attention:

- In NDP literature which, as Krishnan and Ulrich (2001) demonstrate, neglects the upstream phases of the procedure.

- In studies on marketing and sales: the former basically emphasizes the role of tests that can facilitate the take-up of a new product by customers (Manceau, 2003). The later, while emphasizing the role of sales force involvement in the NPD process (Judson et al., 2006), and specifically during launch (di Benedetto, 1999; Michael et al., 2003), is silent on the process of designing the right sales process and the way to integrate sales personnel in the project team.

Yet our research at Telcar demonstrates the impact of this variable and the complexity of this task: it requires consideration of subscription process design, adaptation of tools used by salespeople (particularly Information Systems), training methods for salespeople and the incentives used to mobilize them. This, in line with Judson et al. (2006), underlines the importance of involving the sales department early in design: they are the ones who know the sales process and are capable of anticipating any problems in implementation. Studying innovation in product-related services has thus 


\section{RESEARCH POLICY - FINAL VERSION - OCTOBER 08}

shown us the need to extend concurrent engineering procedures to downstream functional departments, which, up to now, have been little concerned with them. Further study is needed on the roles to be played by these departments, in particular by sales, in the design process. Four problems have consequently appeared: the conditions of involvement, the level of involvement, the training procedure, and the incentive scheme to be established. We discuss them below.

One of the key questions in the E/B call is why the Sales Department was so reluctant to this service? Our observations lead us to propose three explanations. First, E/B call was a radical innovation for Telcar. The service was entirely new to the company. As it is frequently the case in this situation, Telcar General Management pushed it in a top-down manner. Neither the customer, nor the sales department were pulling it. This makes the evangelization more difficult. Second, it was peripheral compared to the mainstream business (i.e. selling cars and the associated traditional, mainly financial, services) whereas, as we show, 1) the E/B call was operationally complex and 2) the rewards for the company were hard to quantify. Finally, the history of the Telematics project was characterized by an important gap between what was announced (value added service like traffic information, music download...) and what was realized. This dampens the expectations of the sales department. In this perspective, the inability to be ready at a new vehicle launch constitutes an important drawback, since this represent a major event in the company's life. These three factors obviously overlap and reinforce each other's to explain the reluctance of the Sales Department regarding the E/B Call. The problem is that this is typical of radical innovations. The question then shift from "why were they reluctant (since they will probably always be)?” to "how to involve and convince them?”. We now turn to this question.

The case studied demonstrates first that we must distinguish two complementary levels of involvement: political and operational. In the E/B Call case, the first level existed, since sales managers took part in project review meetings, whereas the second was clearly absent. However, it is at this level that we find the operational knowledge that will determine the effectiveness of the launch. The questions therefore arise of just how to involve sales staff in the design, and then how to train them. On the first question, recent research (Thomke, 2003; Abramovici and Bancel-Charensol, 2004) demonstrates the necessity of working with one or more pilot branches, which can contribute their 
knowledge about problems of implementation, and can enable procedures to be tested before the launch. We are compelled to recognize that the absence of such a facility was prejudicial to the launch of E/B Call. It probably represents an essential device to integrate sales department in the design process $^{16}$.

Our research also confirms the essential role played by training in the performance of sales staff during launch (Michael et al., 2003). Consequently, raising awareness in the network would seem to be a sine qua non condition for success. This, however, presents real difficulties. In fact, above and beyond the problems of cost and organization involved in such a procedure, designers must take on board the nature of the sales activity itself. Thus, in his research on automobile sales platforms, J. Y. Barbier (2004) shows that the activities and incentives systems of salespeople lead them to concentrate on the most profitable activities. This limits the window of opportunity during which they are available for learning new sales procedures. This "cognitive saturation" of the sales personnel is a constraint for those who design and test sales processes. It limits the time available for training and produces irreversible changes. Once the window of opportunity has been lost, it really is very difficult to retrain sales staff that must take on board a continual stream of new offers (new vehicles, promotions, special editions, and so on).

This brings us to the role of incentive schemes in involving sales staff. The difficulties encountered during the design and launch of E/B Call were in fact magnified by the business model of the service. Indeed, its financing (section 3.1.) leads in fact to a reduction of the profits earned by the dealers on the sales of onboard equipments. This unquestionably explains in part the difficulty of motivating them and is particularly reflected in their absence during pre-marketing tests. Up till now, therefore, salespeople have not viewed E/B Call as a concept that really differentiates them, while at the same time the subscription procedure was considered to be excessively complex. This question nevertheless deserves to have some time spent on it. E/B Call is in fact one of those "pure exploration” situations (Danneels, 2002) in which the company must build up new competencies both

\footnotetext{
${ }^{16}$ For example Electrolux, the leading swedish appliance company, institutionalized a process whereby dealers are involved very early in the innovation process. Specifically they work on the definition of a "selling scenario" i.e. how are they going to sell the product, what are the main arguments... This frequently leads to feedbacks in the definition of the product (Visit to Electrolux, october 2006).
} 


\section{RESEARCH POLICY - FINAL VERSION - OCTOBER 08}

in technical and in marketing terms. In particular, it constitutes a major breach for sales staff that, besides making a sale, literally has to train customers to use it, at a time where they have no prior experience to design an effective process (Michael et al., 2003). Rather than management mistakes, the problems encountered seem to us to be typical of the difficulties that innovations must overcome in large organizations (Dougherty and Hardy, 1996). Incidentally, it is striking to note the similarities between the difficulties encountered by Telcar and those met with by General Motors over telematics services. In their study of the OnStar@ case, Christensen and Roth (2002) showed that GM encountered the same problems when launching the service, despite the training efforts made ahead of time. In both cases the problem was magnified by the nature of the service, which sales staff does not see as a "killer app”, and by the absence (or in GM's case, slenderness) of financial incentives to sell the service, an absence that can be largely explained by the strained relationship with the Sales Department.

Consequently, the design of an incentive scheme to facilitate first staff involvement and then sales of an innovative service constitutes an important question for research. Thomke (2003) has demonstrated that for banking services it is difficult to design an incentive scheme that, while favouring the involvement of front-office staff in the innovation process, does not have a negative impact on the performances of day-to-day activities (mainly sales growth and customer satisfaction). Our study confirms this result in the case of a breakthrough innovation. Furthermore this emphasizes the importance of "complete” front-loading in design: E/B Call shows the need to get started very early on sales involvement, training and generating awareness within the network. More precisely we believe that the involvement of sales in the innovation process presuppose the alignment of evangelization at all level, organization and incentives. The E/B call suffers from misalignment, but this a likely to be the case in most situations of exploration. This doubtless represents a challenge for the "sales methods" that need to be integrated into the design process so as to make the sales process a key lever in getting the innovation adopted. 


\subsection{Managing after sale learning in users communities: theoretical insights.}

However, the previous discussion can lead to a more radical proposition: the anticipation strategy will lead to poor results not only because upfront involvement of sale professionals is difficult, but also because the sales process is not an appropriate situation for customer learning. Indeed, without a deep reorganization of the car dealer network, sales will go on being an intense interaction, a drama dedicated to trigger off the car buying from the customer and to negotiate its price from the salesman. In this context, explaining in details of an innovative service will always be a secondary goal, both from the salesman and customer point of view.

In fact, as we noted previously, marketing people insist on the impact of "simplicity", "easy to use”, “clarity”, etc. of new product on sales efficiency. The underlying hypothesis is that sale is easy when commercial interaction can rely on existing knowledge from the customers: he appreciates the value of the innovation because he has a personal experience of its use and he is confident in his ability to use it. Considering the auto case, at least two types of innovations can rely on this process:

- Innovations that embed users' competence into technical systems through automation: automatic headlight and windshield, ESP, etc. are good examples of such innovations;

- Innovations that exploit knowledge that the customer had already learned in another situation (Midler, 2007). Auto-radio for example just transferred in car the radio experience that the drivers achieved at home in the 1950's. Today sophisticated car entertainment systems follow up the same track.

This leads to a paradox since the more novel the innovation, the less marketable it is. Telematic services provide a good example of this pessimistic, but realistic, proposition. In the 1990's, market studies emphasized the development of "car centric" services such as Ecall, info traffic, GPS navigation systems as best valuable innovations for drivers. But on the contrary, these markets took 10 years to take off, and grew up in the mid 2000's after the customer could experience those systems on smart-phones or PDA.

From our case and other examples (think for example about Apple's strategy to launch the iPhone) we can identity three steps in the marketing of innovative product-related services. 
1. The sales process is focused on the physical characteristics of the product. As the value of the service is difficult to show during the short and paroxysmal momentum of the sales drama, the process is focused on other attributes of the product value (esthetics, symbolic...) generally embedded in the physical design of the product: typically, a great color screen, a beautiful design, a spectacular interface, and so on. Indeed our data shows that the salesmen were mostly selling an onboard equipment allowing navigation, not the E-call.

2. A "test period" delaying full price. The institution of a "test period" is a usual strategy to market new services. It lowers the barrier to entry and favor impulsive buying. Moreover it gives the customer the opportunity to learn and appreciate the reality of the value of the service that he cannot have beforehand.

3. After-sales users community management to support user learning. In this perspective hotlines and other assistance processes plays a crucial role to support user learning. Indeed such ex-post information for users have various advantages compared to ex ante communication on the innovation. First, it is restricted to those who have already bought the product. This is less expensive that a systematic information to every potential customer and more efficient, because it is driven by the customer motivation to understand and use efficiently what he has bought. Second, customers' feedbacks can rapidly lead to define efficient advices for the users community and lead to efficient evolutions of the service.

This leads to an important evolution in the role of after-sales processes. Indeed the goal here, rather than correcting mistakes or providing basic advices, is to support the customer learning-by-using process (Rosenberg, 1982). It takes into account the fact that the customer creates the value of an innovative service when he uses it, and thus discovers its possibilities. This question deserves further research since it very probably supposes an increase in the knowledge content of after-sales.

\section{Conclusion: Learning, limitations and further research.}

The development of product-related services is becoming a key strategy for industrial firms. However, has we have shown, this suppose an important evolution in the management of the NPD process. Based on both theoretical arguments and empirical case material, this paper provides an 


\section{RESEARCH POLICY - FINAL VERSION - OCTOBER 08}

analysis of the limitations of traditional NPD process, especially concerning the "moment of truth" of the technical ramp-up and commercial launch. This leads us to propose two complementary strategies to enhance the efficiency of PRS launch.

In this way, this paper 1) helps extend studies on NPD downstream of the design process (Krishnan and Ulrich, 2001), 2) reinforce empirical foundations on the link between NPD and sales management and 3) contribute to the growing body of research on innovation in services. Thus, the E/B Call case study has helped to demonstrate the specific features of a service launch. This involves simultaneously managing two processes that are relatively separate in the case of products: the rampup of the production system and the launch itself. Nevertheless, this specificity does not render irrelevant the results presented in the literature on ramp-up. Our research therefore confirms that the findings obtained for physical goods hold good for services as well, and extends them to cover downstream specializations, in particular, sales. Consequently, we recognize:

- The importance of the quality of the upstream design work for performance and, conversely, the negative impact of late changes;

- The role of management structures in this phase: first, they help to manage the problems that inevitably appear; and, secondly, they help to capitalize on the knowledge accumulated so as to guide the process in real time.

Our research has also identified key issues for research into innovation. First, the design of the sales process and its impact on the adoption of innovations is a field that has been little explored in the literature. The case studied here illustrates the difficulties experienced in involving these personnel and the need to align evangelization, organization and incentives. The methods used to involve them undoubtedly constitute an emerging field of research. This brings up both the role and the form of the tests conducted during the design process, which must make it possible to test this dimension, and of the incentive schemes for personnel who are systematically swamped in their day-to-day tasks. This research then contributes to the emerging literature on sales learning curves (Leslie and Holloway, 2006). Studying the ways salespeople learn and opportunities for influencing this is another important issue that we have barely touched upon here. Furthermore, we point out that the management of customer learning is a key question that cannot be limited to sales per se since it certainly suppose to 


\section{RESEARCH POLICY - FinAL VERSION - OCTOBER 08}

reinvent the role of after-sale. No doubt that the questions raised call for innovative collaboration between the disciplines involved (marketing, sales, new product development and innovation management).

The research reported here draws on one case within a single research setting. Its findings should thus obviously be treated with healthy caution. In retrospect, the characteristics of the case probably affect the research findings. We consider it important to note the following four points:

- In the first place we have only studied a single car manufacturer. And even though we have observed phenomena that are similar to those evinced by Christensen \& Roth and Thomke, it would be advantageous to study other manufacturers and other sectors, specifically "pure" service firms;

- Indeed we're in the case of product-related services in an industry with a long tradition of project management in vehicle design. This has unquestionably some implications: it complicates the process since the team has to coordinate with the vehicle (which set the pace) and the support product, and the services are always perceived as peripheral. The analysis of this characteristics on the unfolding on the service innovation process deserves further research;

- Furthermore, E/B Call constitutes a breakthrough innovation which, up to the time of writing, has not been seen as a "killer app", at least in the sales department;

- Finally, the launch did not benefit from concomitant modifications of the incentive scheme for motivating the sales force.

So we have found ourselves in the least favourable case, and it would be interesting to study the launch of some innovations that are less dramatic and more attractive for the network, so as to study the impact of these variables on the involvement of sales staff in the design process.

\section{Acknowledgements}

We thank two sets of three anonymous reviewers for suggestion on how to improve the paper. We also are grateful to T. Globokar, S. Jouini, F. Charue, R. Teulier, T. Paris and N . Raulet for their comments and support during the writing of this paper. We are especially imdebted to C. Loch for many useful suggestions on a previous version of this paper. 


\section{RESEARCH POLICY - FINAL VERSION - OCTOBER 08}

\section{$\underline{\text { References }}$}

Abramovici M., Bancel-Charensol L., 2004. How to take consumer into consideration in service innovation projects ?, The Service Industries Journal 24 (1), 56-78.

Adler, P., K. Clark., 1991. Behind the learning curve : a sketch of the learning process. Management Science. 37 (3), 267-281.

Alam, I., 2002. An exploratory investigation of user involvement in new service development, Journal of the Academy of Marketing Science 30 (3), 250-61.

Barbier, J.Y., 2004. Efficacité et transposabilité d'une plate-forme de vente. Le cas d'une entreprise de distribution de véhicules d’occasion. Unpublished Ph.D Thesis, Ecole Polytechnique, Paris, France

Brown, S.L., Eisenhardt, K.M., 1995. Product development: past research, present findings, and future directions. Academy of Management Review 20 (2), 343-378.

Charue-Duboc, F., 1995. Usage et production de connaissance dans une usine automobile : un processus d'apprentissage organisationnel in F. Charue-Duboc (eds.). Des savoirs en action, L’Harmattan, Paris, 175-198.

Christensen C., Roth, E., 2002. OnStar : Not Your Father’s General Motors (A). Harvard Business School Case 9-602-081.

Clark, K., Fujimoto, T., 1991. Product development performance. Strategy, organization and management in the world auto industry, Harvard Business School Press, Cambridge, MA.

Cooper, R., 1993. Winning at new product : accelerating the process from idea to launch, $2^{\text {nd }}$ edition, Addison-Wesley.

Cusumano, M., 2004. The business of Software, The Free Press.

Danneels, E., 2002. The dynamics of product innovation and firm competences. Strategic Management Journal 23 (12), 1095-1121.

di Benedetto A. 1999. Identifying the Key Success Factors in New Product Launch. Journal of Product Innovation Management 16(6), 530-544. 


\section{RESEARCH POLICY - FINAL VERSION - OCTOBER 08}

Dougherty, D., Hardy C., 1996. Sustained product innovation in large, mature organizations: overcoming innovation-to-organization problems. Strategic Management Journal 39 (6), 11201153.

Dutton, J., Thomas, A., 1984. Treating progress functions as managerial opportunities. Academy of Management Review 9 (2), 235-247.

Edvardsson, B., Gustafsson, A., Johnson, M.D., Sanden, B.. 2000. New service development and innovation in the new economy, Studenlitteratur, Lund, Sweden.

Eiglier, P., Langeard, E., 1987. Servuction. Le marketing des services. Edisciences International, Paris, France.

Eisenhardt, K., 1989. Building theories from case study research. Academy of Management Review. 14 (4), 532-550.

Furrer, O., 1997. Le rôle stratégique des services autour du produit. Revue Française Gestion. 113, 98-107.

Gadrey, J., 2003. Socio-économie des services. La Découverte, Paris, France.

Gallouj, C., Gallouj, F., 1996. L’innovation dans les services. Economica, Paris, France.

Gawer, A., Cusumano, M., 2003. Platform leadership. Harvard Business School Press, Cambridge, MA.

Grönroos, C., 1990. Service Management and Marketing : Managing the moments of Truth in Service Competition. Lexington Books, New York.

Hultink E, Atuahene-Gima K. 2000. The Effect of Sales Force Adoption on New Product Selling Performance. Journal of Product Innovation Management 17(6), 435-450

Jallat F. 2000. Le management de l'innovation dans les entreprises de services: spécificité des processus et facteurs de performances. In : Bloch A., D. Manceau D. (eds), De l’idée au marché, Vuibert, Paris, France

Judson, K., Schoenbachler, D., Gordon, G., Ridnour, R., Weilbacker, D., 2006. The new product development process: let the voice of the salesperson be heard. Journal of Product \& Brand Management 15(2/3), 194-202. 


\section{RESEARCH POLICY - FINAL VERSION - OCTOBER 08}

Kingman-Brundage, J., 1989. The ABCs of service blueprinting. In: Bitner M.J., Crosby L.A. (eds), Designing a winning service strategy, American Marketing Association.

Kotler, A., 2003. Marketing Management. Pearson Education, France.

Krishnan, V., Ulrich, K., 2001. Product development decisions : a review of the literature. Management Science 47 (1), 1-21.

Langowitz, N., 1988. An exploration of production problems in the initial commercial manufacture of products. Research Policy 17, 43-54.

Lapre M., Mukherjee A.S., Van Wassenhofe, L., 2000. Behind the learning curve : linking learning activities to waste reduction. Management Science 46 (5), 597-611.

Lenfle, S., Midler, C., 2001. Innovation-based competition and the dynamics of design in upstream suppliers, International Journal of Automotive Technology and Management, 1 (2/3), 269-286.

Lenfle, S., Midler, C., 2003. Innovation in automotive telematic services : characteristics of the field and management principles. International Journal of Automotive Technology and Management, 3 144-159.

Lenfle, S., 2004. Innovation in services : the contribution of design theory. 11th International Product Development Management Conference - Dublin, june 20-22.

Leonard-Barton, D. 1988. Implementation as mutual adaptation of technology and organization. Research Policy 17 (5), 251-267.

Leslie, M. Holloway, C.A. 2006. The sales learning curve. Harvard Business Review, July-August. Lieberman, M.B., Montgomery, D.B., 1988. First-mover advantage. Strategic Management Journal 9 (6), 41-58.

Lovelock, C., Wirtz, J.., Lapert, D., 2004. Marketing des services. Pearson Education, Paris, France.

Lovelock C., 1984. Developing and implementing new services. In: George, W., Marshall, C., (eds.), Developing new service, American Marketing Association.

Magnusson, P., 2003. Customer-Oriented Product Development. Experiments Involving Users in Service Innovation. Unpublished PhD. Dissertation. EFI, The Economic Research Institute. Stockholm School of Economics: Stockholm 


\section{RESEARCH POLICY - FinAL VERSION - OCTOBER 08}

Manceau, D., 2003. Lancement de nouveaux produits. In: Mustar, P., Penan, T,. (eds.), Encyclopédie de l'innovation. Economica, Paris, France.

Michael K, Rochford L, Wotruba T. 2003. How New Product Introductions Affect Sales Management Strategy: The Impact of Type of "Newness" of the New Product. Journal of Product Innovation Management 20 (4), 270-283.

Midler C. 2007. Expansion des produits, des usages, des marchés et dynamique du système de conception: l'exemple de la voiture communicante. In Hatchuel, A., Weil, B., (Eds.), Les nouveaux régimes de la conception. Vuibert: Paris

Miles, M., Huberman, M., 1994. Qualitative Data Analysis, Sage Publications.

Moore, G.A., 1995. Inside the Tornado. HarperBusiness Book, New-York.

Rogers, E., 1983. Diffusion of Innovations. The Free Press.

Rosenberg, N., 1982. Inside the Black Box: Technology and Economics. Cambridge University Press: New-York

Scheuing, E., Johnson, E., 1989. A proposed model for new service development. Journal of Service Marketing 3 (2), 25-34.

Shostack, G.L., 1981. How to design a service ? in: W., J. Donnelly (eds.), Marketing of services. George, American Marketing Association proceedings series.

Terwiesch, C. \& Bohn, R., 2001. Learning and Process Improvement during Production Ramp-u, International Journal Production Economics (70), 1-19.

Terwiesch, C., Chea, K., Bohn, R., 1999. An Exploratory Study of Product Transfer and Production Ramp-up in the Data Storage Industry, Report 99-02, Graduate Scholl of International Relations and Pacific Studies, University of California, San Diego.

Terwiesch, C., Xu, Y., 2001. The Hidden Cost of Process Change during Production Ramp-up, Working Paper, Warthon School.

Thomke, S., 2003. R\&D comes to service. Bank of America’s pathbreaking experiment. Harvard Business Review, April, 71-79. 
Van de Ven A, Polley D, Garud R, Venkataraman S., 1999. The innovation journey. Oxford University Press, New-York

Von Hippel, E., Tyre, M., 1995. How learning by doing is done : problem identification in novel process equipment. Research Policy 24, 1-12.

Wheelwright, S., Clark, K., 1992. Revolutionizing product development. Quantum leaps in speed, efficiency and quality. The Free Press, New-York.

Yin, R. 2003. Case Study Research. Design and Methods. ( $3^{\text {rd }}$ ed.) Sage Publications.

Zeithaml , V., Parasuraman, A., Berry, L., 1990. Delivering Quality Services. The Free Press, New York. 


\section{FIGURES}

Figure 1 The relationship between goods and service content for a range of products. (Magnusson, 2003)

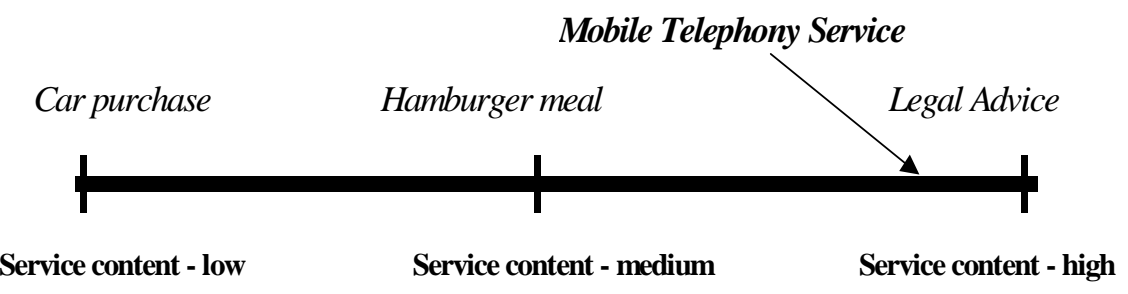

Figure 2: A simplified blueprint of the E/B Call.

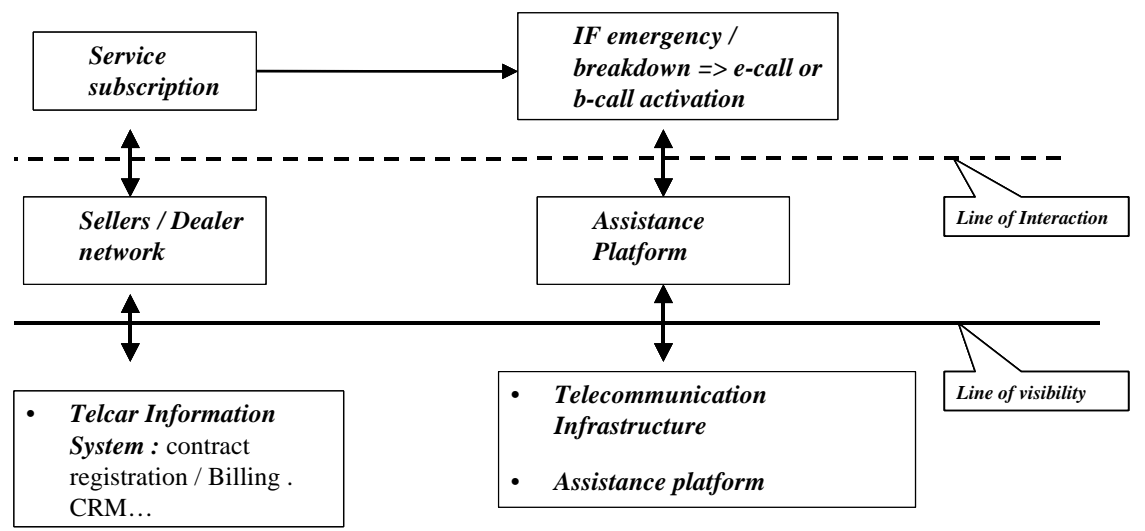

Figure 3: principal events and participants in the design process

\begin{tabular}{|c|c|c|c|c|c|c|c|c|c|}
\hline \multirow[b]{2}{*}{ Trimestre } & \multicolumn{4}{|c|}{2001} & \multicolumn{4}{|c|}{2002} & \multirow{2}{*}{$\begin{array}{c}2003 \\
1\end{array}$} \\
\hline & 1 & 2 & 3 & 4 & 1 & 2 & 3 & 4 & \\
\hline $\begin{array}{c}\text { Process } 1 \text { : service } \\
\text { infrastructure design }\end{array}$ & \multicolumn{5}{|c|}{ Design and implementation of the infrastructure } & $\begin{array}{c}\text { Failure of the } \\
\text { tests }\end{array}$ & redesign & $\begin{array}{c}\text { Final } \\
\text { agreement }\end{array}$ & \multirow{2}{*}{$\begin{array}{c}\text { Service } \\
\text { launch (12 } \\
\text { month delay) }\end{array}$} \\
\hline $\begin{array}{c}\text { Process } 2 \text { : } \\
\text { sales process design }\end{array}$ & \multicolumn{3}{|c|}{ First version of the sales process } & \begin{tabular}{|c|} 
Conflict with \\
sales dep.
\end{tabular} & & \multicolumn{2}{|c|}{$\begin{array}{l}\text { Sales person involved (april) } \\
\text { / design v2 }\end{array}$} & $\begin{array}{c}\text { Final } \\
\text { agreement }\end{array}$ & \\
\hline \multicolumn{10}{|l|}{ Departments involved } \\
\hline \multicolumn{10}{|l|}{ Telematic platform } \\
\hline \multicolumn{10}{|l|}{ Information systems* } \\
\hline \multicolumn{10}{|l|}{ Product** } \\
\hline \multicolumn{10}{|l|}{ CRM* } \\
\hline \multicolumn{10}{|l|}{ After-sales* } \\
\hline Sales & \multicolumn{4}{|c|}{ 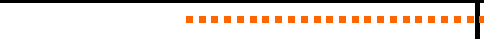 } & $= \pm$ & \multicolumn{4}{|c|}{ 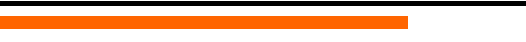 } \\
\hline Legal & & & & & & \multicolumn{4}{|c|}{ } \\
\hline
\end{tabular}

$*=1$ person dedicated to telematics but not full time on the $\mathrm{E} / \mathrm{B}$ call

** $=2$ persons dedicated to telematics but not full time on the $\mathrm{E} / \mathrm{B}$ call

Note that this representation simplifies the reality. For example there is in fact three different departments involved in what we call "Sales" : Operational marketing / Sellers training / Dealer network management. 
Figure 4: The emergency call service: 17 months of operation

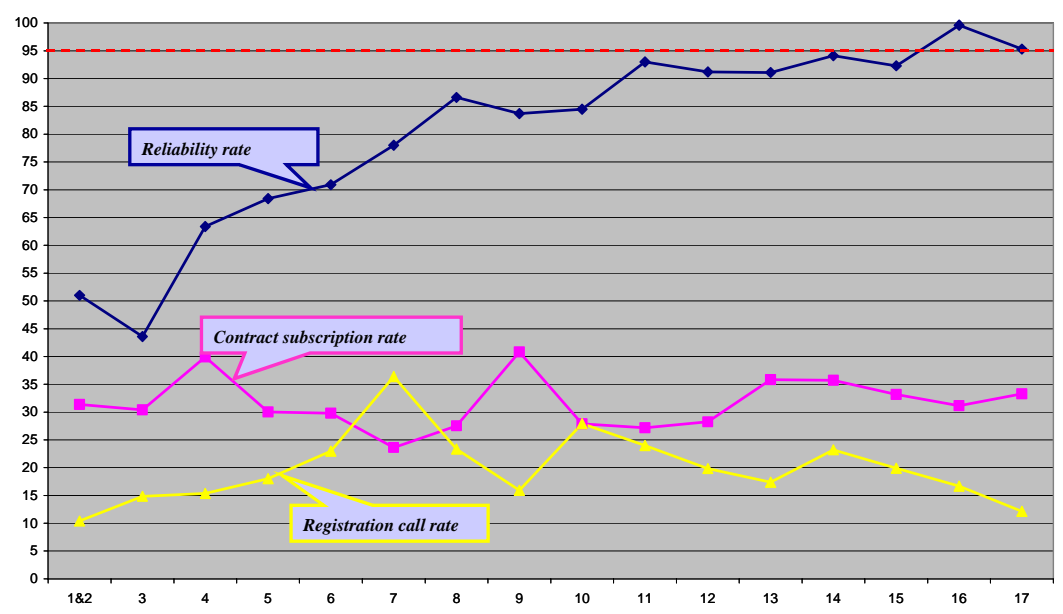

Figure 5: Reliability of vehicle location between the fourth and eighth months following launch

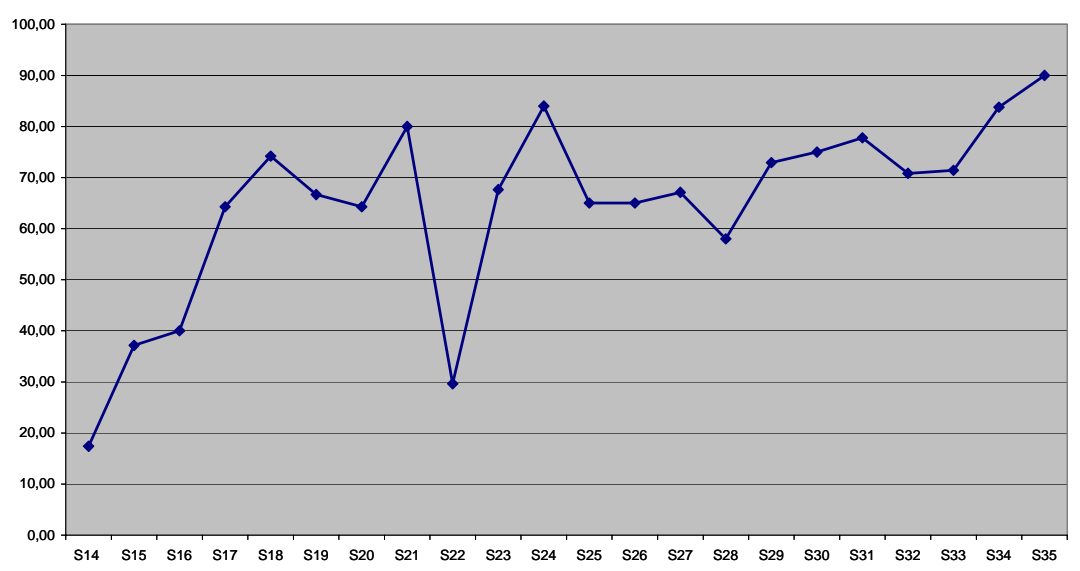

